G420(P) A RARE CASE OF SYNDROMIC CONGENITAL HYPERINSULINISM IN A PRETERM BABY

R Oba, U Aboushofa, B Olorunsola. Paediatrics, North Lincolnshire and Goole NHS FT, Scunthorpe, UK

\subsection{6/archdischild-2020-rcpch.362}

Clinical Case Presentation A case of Syndromic Congenital Hyperinsulinism in a preterm baby, caused by Beckwith-Weidemann Syndrome(BWS) was seen in our unit. Baby was born at 34 week gestational age by emergency lower segment caesarean section, as a result of fetal distress. Baby was noted to be macrosomic at birth with a weight of $4.37 \mathrm{~kg}$ (above the 99.6th centile) and transverse earlobe crease with post-auricular pits. However, there was no other clinical features of Beckwith-Wiedemann Syndrome noted.

Baby was born to a $30 \mathrm{yr}$ old primigravida lady with high BMI of 47. Antenatal Gestational Diabetic screening with oral glucose tolerance test was negative on three separate occasions. There was no history of Polyhydramnious. Anomaly scan was normal. Both parents are non-consanguineous. Dad suffers from Watson Syndrome(a variant of Neurofibromatosis type1) and Mum is Healthy, apart from unexplained High BMI.

Baby was born in good condition but developed respiratory distress soon after birth. Baby was therefore admitted to NICU requiring respiratory support via vapotherm. Baby was noted to have developed hypoglycaemia within the first hours of birth.

Management Hypoglycaemia persisted despite initial 10\% dextrose mini-boluses, 20\% dextrose and 50\% dextrose infusion. Baby required up to $20 \mathrm{mg} / \mathrm{kg} / \mathrm{min}$ of dextrose infusion including oral feeds. Normoglycaemia was eventually achieved with Glucagon infusion 5 microgram $/ \mathrm{kg} /$ hour and sustained on oral Chlorothiazide at $7 \mathrm{mg} / \mathrm{kg} / \mathrm{day}$, as well as Diazoxide at 5 $\mathrm{mg} / \mathrm{kg} /$ day.

Insulin level was raised at $98 \mathrm{pmol}$, as well as C-peptide at 1812 pmol at the time of hypoglycaemia. Baby has a normal Growth Hormone, cortisol level. Ammonia, plasma Amino Acids were also within normal limits.

Baby has clinical and radiological signs of hepatomegaly but normal sized kidneys and pancreas. Echocardiography showed septal and ventricular wall hypertrophy.

In view of macrosomia, transverse earlobe crease with post auricular pits,hyperinsulinism and hypoglycaemia genetic test for BWS was sent.

The genetic testing showed Hypomethylation at KCNQ10T1:TSS-DMR(11P15.5) confirming Beckwith-weiderman Syndrome (BWS)

Conclusion This case exemplified a rare case of Beckwith-weidermann diagnosed in a preterm baby, presenting with Congenital Hyperinsulinism. BWS is associated with preterm delivery in $43 \%$ of reported cases. Early suspicion and diagnosis improve outcome.

\section{G421(P) INCIDENCE AND MANAGEMENT OF DIABETIC KETOACIDOSIS IN CHILDREN WITH TYPE 1 DIABETES MELLITUS}

${ }^{1}$ NAEE Hanna, ${ }^{2}$ RM Williams, ${ }^{1,2}$ AEJ Hendriks. ${ }^{1}$ Department of Paediatrics, University of Cambridge, Cambridge, UK; ${ }^{2}$ Department of Paediatric and Adolescent Diabetes and Endocrinology, Cambridge University Hospitals NHS FT, Cambridge, UK

10.1136/archdischild-2020-rcpch.363
Aims Analyse incidence of diabetic ketoacidosis (DKA) over time in children with type 1 diabetes mellitus (T1DM).

Audit compliance with 2015 NICE guidelines on DKA management in children with T1DM.

Methods Audit of children $<16$ years of age with T1DM in a single academic centre. DKA admissions were identified from electronic records. Data was collected from 01/01/2011 until 31/12/2012 and from 01/01/2017 until 31/12/18. Pearson ChiSquare test compared DKA incidence between time periods. Local DKA guidelines were updated in July 2016. Audit data was therefore collected between 01/08/2016 and 31/12/2018. DKA management was evaluated by 6 standards: DKA diagnosis, estimation of dehydration, fluid calculation, intravenous fluid type and insulin dose and timing.

Results A total of 612 children were included, 283 in 2011/ 12 and 329 in 2017/18. There were 81 and 73 hospital admissions in $2011 / 12$ and $2017 / 18$, respectively. There was a significant decrease in admissions for DKA from 25 (31\%) admissions in 2011/12 to 11 (15\%) admissions in 2017/18 $(p=0.02)$. There was no difference between time periods in whether DKA admissions were at diagnosis of T1DM (15 $(60 \%)$ in $2011 / 12 ; 8$ (73\%) in 2017/18).

Between 01/08/2016 and 31/12/2018, 371 children were audited. Seventeen admissions for DKA out of 91 total hospital admissions (19\%) were included. Newly diagnosed T1DM accounted for 33 (36\%) admissions, hypo- and hyperglycaemia for another $17(19 \%)$ and $24(26 \%)$ admissions were due to other reasons. DKA diagnosis was appropriate in 17/17 $(100 \%)$ admissions. Estimation of dehydration was correct in 16/17 (94\%) admissions. Fluid requirement calculation was accurate in 16/17 (94\%) admissions. Appropriate intravenous fluids were started in 16/17 (94\%) admissions. The correct intravenous insulin dose was given in 16/17 (94\%) admissions, and this was started $>1$ hour after starting intravenous fluids in 16/17 (94\%) admissions. Overall, only $12 / 17$ (71\%) admissions were fully managed according to DKA guidelines on these key standards.

Conclusions DKA admission incidence has significantly decreased in our hospital in 2017/18 compared to 2011/12. Compliance with DKA guidelines on management was suboptimal and further education of healthcare professionals is required.

\section{G422(P) THE USE OF SOCIAL MEDIA TO IMPROVE DIABETES RELATED HEALTH LITERACY IN PARENTS OF A TYPE 1 DIABETES CLINIC COHORT}

${ }^{1} \mathrm{D}$ Greene, ${ }^{2} \mathrm{~K}$ Matyka. ${ }^{1}$ Paediatrics, Royal Surrey County Hospiital, Guildford, UK; ${ }^{2}$ Post Graduate, University of Warwick, Warwick, UK

\subsection{6/archdischild-2020-rcpch.364}

Background Social media use is becoming more common in people with chronic illness.

Objective To determine if posts to a Facebook page can be used to increase the Health Literacy of parents of children with Type 1 Diabetes.

Methods All parents of the 149 children served by a clinic in a district general hospital were invited to join a purpose created Facebook group. Specific health related information was posted regularly and the change in Health Literacy was measured pre and post-intervention using a validated questionnaire. Results Half of the 10 questions showed improvement in Health Literacy score post-intervention. Parents were more 